\title{
Laparoscopic Adjustable Gastric Band: Complications, Removal and Revision in a Portuguese Highly Differentiated Obesity Treatment Center
}

\author{
Banda Gástrica Ajustável por Laparoscopia: Complicações, Remoção e Revisão \\ num Centro Português Altamente Diferenciado no Tratamento da Obesidade
}

\author{
Alfredo MENDES-CASTRO $\square^{1,2}$, Joana MONTENEGRO², Jorge Félix CARDOSO $^{2}$, Gisela SIMÕES ${ }^{2}$, Catarina FERREIRA², \\ John PRETO ${ }^{2,3}$, Silvestre CARNEIRO 2,3 \\ Acta Med Port 2015 Nov-Dec;28(6):735-740
}

\section{ABSTRACT}

Introduction: Our objective is to determine which complications lead to reoperation, and the outcomes of reoperation using laparoscopic adjustable gastric banding, laparoscopic Roux-en-Y gastric bypass and laparoscopic sleeve gastrectomy at Centro Hospitalar de São João.

Material and Methods: Observational study. Patients included were aged 18 to 65 years at first gastric banding, underwent removal from March $21^{\text {st }} 2007$ to January $23^{\text {rd }} 2014$ and were subsequently converted to gastric banding, gastric bypass or sleeve gastrectomy. Women who got pregnant during the initial gastric banding follow-up and patients that performed more than one conversion were excluded.

Results: A total of 103 patients were included. Fifteen underwent revision to gastric banding, 71 to gastric bypass and 17 to sleeve gastrectomy. Respectively, percentage of excess weight loss at 1 month were $1.9 \pm 12.2 \%$ in 6 patients, $36.9 \pm 18.2 \%$ in 49 patients and $27.1 \%$ (13.3 - 68.6) in 11 patients (laparoscopic adjustable-gastric banding-laparoscopic Roux-en-Y gastric bypass $p<0.001$, laparoscopic adjustable-gastric banding-laparoscopic sleeve gastrectomy $p=0.002$ and laparoscopic Roux-en-Y gastric bypass-laparoscopic sleeve gastrectomy $p=0.474)$. At 3 months there were $12.8 \%(5.7-84.8)$ in 6 patients, $44.8 \pm 19.7 \%$ in 24 patients and $48 \pm 20.1 \%$ in 8 patients (laparoscopic adjustable-gastric banding-laparoscopic Roux-en-Y gastric bypass $p=0.017$, laparoscopic adjustable-gastric banding-laparoscopic sleeve gastrectomy $p=0.039$ and laparoscopic Roux-en-Y gastric bypass-laparoscopic sleeve gastrectomy $p=0.691$ ).

Discussion: At revision, ages and body mass indices are higher than other studies. Gastric bypass is the preferred revision surgery, because combines restriction and malabsorption, surgeons have more experience and long term outcomes are better described.

Conclusions: The main indications for reoperation were inadequate weight loss (37.4\%) and band slippage (30\%). At short term, in our patients, gastric banding as a revision surgery was not effective, as opposed to gastric bypass and sleeve gastrectomy.

Keywords: Gastroplasty; Laparoscopy; Obesity, Morbid/surgery.

\section{RESUMO}

Introdução: Pretendemos determinar que complicações levaram a reoperação, e os resultados da reoperação com banda gástrica ajustável por laparoscopia, do bypass gástrico em Y de Roux por laparoscopia e da gastrectomia em sleeve por laparoscopia, no Centro Hospitalar de São João.

Material e Métodos: Incluímos indivíduos dos 18 aos 65 anos na primeira banda gástrica ajustável por laparoscopia, cuja remoção ocorreu entre 21 de Maio de 2007 e 23 de Janeiro de 2014 e depois convertidos para banda gástrica, bypass gástrico ou gastrectomia em sleeve. Excluímos mulheres que engravidaram no primeiro seguimento e indivíduos submetidos a mais de uma conversão.

Resultados: Incluímos 103 indivíduos. Quinze convertidos em banda gástrica, 71 em bypass gástrico e 17 em gastrectomia em sleeve. Respectivamente, no primeiro mês, as percentagens de excesso de peso perdido foram: 1,9 $\pm 12,2 \%$ em seis indivíduos, 36,9 $\pm 18,2 \%$ em 49 indivíduos e $27,1 \%(13,3-68,6)$ em 11 indivíduos (laparoscopic adjustable-gastric banding-laparoscopic Roux-en-Y gastric bypass $p<0,001$, laparoscopic adjustable-gastric banding-laparoscopic sleeve gastrectomy $p=0,002$ e laparoscopic Rouxen-Y gastric bypass-laparoscopic sleeve gastrectomy $p=0,474)$. No terceiro mês, foram: $12,8 \%(5,7-84,8)$ em seis indivíduos, 44,8 $\pm 19,7 \%$ em 24 indivíduos e $48 \pm 20,1 \%$ em oito indivíduos (laparoscopic adjustable-gastric banding-laparoscopic Roux-en-Y gastric bypass $p=0,017$, laparoscopic adjustable-gastric banding-laparoscopic sleeve gastrectomy $p=0,039$ e laparoscopic Roux-en-Y gastric bypass-laparoscopic sleeve gastrectomy $p=0,691$ ).

Discussão: Na revisão, as idades e os índices de massa corporal são superiores a outros estudos. O bypass gástrico é o método de revisão preferido pela restrição e malabsorção, pela maior experiência de execução e pelos resultados a longo prazo melhor estudados.

Conclusões: As principais indicações para reoperação foram perda de peso inadequado (37,9\%) e deslocamento de banda (34\%). A curto prazo, na nossa amostra, a revisão com banda gástrica não foi efectiva, diferente dos bypass gástrico e gastrectomia em sleeve. Palavras-chave: Gastroplastia; Laparoscopia; Obesidade Mórbida/cirurgia.

\footnotetext{
1. Center for Research in Health Technology and Services Research (CINTESIS). Porto. Portugal.

2. Faculty of Medicine. University of Porto. Porto. Portugal.

3. Surgery Department. Centro Hospitalar de São João. Porto. Portugal.

$\bowtie$ Autor correspondente: Alfredo Mendes de Castro. alfredomendescastro@gmail.com

Recebido: 05 de Março de 2015 - Aceite: 21 de Julho de 2015 | Copyright @ Ordem dos Médicos 2015
} 


\section{INTRODUCTION}

Since 1980 obesity has duplicated its prevalence and became a pandemic. In 2008, more than 1.4 billion people with 20 or more years of age were overweight. From these, approximately 200 million men and 300 million women were obese. Worldwide, this contributes to 2.8 million deaths per year in adults and approximately 33 million disabilityadjusted life years. ${ }^{1-3}$ In Portugal, in 2008, $59.7 \%$ of men and $50.8 \%$ of women were overweight and $20.4 \%$ of men and $22.3 \%$ of women were obese. ${ }^{4}$

Bariatric surgery remains the most effective treatment option achieving sustained weight loss over time, improvement or resolution of comorbidities, and reduction of mortality and morbidity. ${ }^{5-10}$ In 2011, approximately 113 thousand procedures were performed in Europe. Roux-en-Y gastric bypass (RYGB) represented $43.5 \%$ of all procedures done, sleeve gastrectomy (SG) $27.8 \%$, laparoscopic adjustable-gastric banding (LAGB) $17.8 \%$ and biliopancreatic diversion with duodenal switch (BPD/DS) $2.1 \% .^{11-14}$

LAGB is considered a restrictive reversible procedure, presenting a shorter learning curve than other techniques. However, LAGB failure rates are reported to be as high as $40 \%-50 \%$ with revision rates up to $20 \%-30 \% .^{15}$ The most common early complications reported are gastric perforation, band or port-site infection, band obstruction, malposition and late complications such as band slippage, band erosion, band dysfunction, pouch enlargement, esophageal dilation and gastroesophageal reflux (GER). There is also the possibility of wound infection, incisional hernia, symptomatic cholelithiasis, nausea, vomiting, intraabdominal bleeding and pulmonary embolism. ${ }^{16}$ When inadequate weight loss or complications occur, rebanding or conversion to RYGB, SG or BPD/SD may be an option. ${ }^{15,16}$ It has been suggested that the redo procedure selection should be based on several factors, including patient history and intraoperative findings. ${ }^{15}$

The Portuguese reality is not well studied. In 2008, 1323 bariatric surgeries were performed and in 2011, out of 3028 bariatric procedures, 684 were LAGB. ${ }^{13,14}$ However, there is no recent data specifically addressing the outcomes of LAGB, how these cases are managed when they fail and what the outcomes of the management are.

The purposes of this study were to describe the complications that lead to rebanding or conversion to laparoscopic Roux-en-Y gastric bypass (LRYGB) and laparoscopic sleeve gastrectomy (LSG), and to compare the outcomes of revision weight loss surgery (RWLS) in the Surgery Department of Centro Hospitalar de São João (CHSJ).

\section{MATERIAL AND METHODS \\ Study design}

Observational, longitudinal and retrospective study.

\section{Selection of participants}

We included patients who fulfilled the following criteria: age between 18 and 65 years at first LAGB procedure; LAGB removal for the first time performed from March $21^{\text {st }}$ 2007 to September $1^{\text {st }} 2014$ at the Surgery Department of CHSJ; converted to LAGB, LRYGB or LSG. Women who got pregnant during the first LAGB's follow-up and patients that underwent more than one conversion procedure were excluded from the study.

\section{Data collection}

Data was collected from the electronic health record (EHR) from CHSJ after approval from the Health Ethics Committee. The patient's record numbers were obtained from SONHO (Integrated System of Hospital Information) using the code 44.97 of the International Classification of Diseases $9^{\text {th }}$ Edition. Inclusion and exclusion criteria were applied to this pool of patients to select the individuals of interest. The variables collected included socio-demographic characteristics, operative details, complications, weight, body mass index (BMI), excess weight (EW) and percentage of excess weight loss (\%EWL). All data of interest available up to September $12^{\text {th }} 2014$ was collected.

\section{Data analysis}

Parametric data is presented as mean \pm standard

Table 1 - Indications and type of revision weight loss surgery (RWLS)

\begin{tabular}{lcccc}
\hline Indications for revision & $\begin{array}{c}\text { LAGB group } \\
(\mathrm{n}=15)\end{array}$ & $\begin{array}{c}\text { LRYGB group } \\
(\mathrm{n}=71)\end{array}$ & $\begin{array}{c}\text { LSG group } \\
(\mathrm{n}=17)\end{array}$ & $\begin{array}{c}\text { TOTAL } \\
(\mathrm{n}=103)\end{array}$ \\
\hline Inadequate weight loss (\%) & $0(0)$ & $33(46.5)$ & $6(35.3)$ & $39(37.9)$ \\
Band slippage (\%) & $13(86.7)$ & $14(19.7)$ & $8(47.1)$ & $35(34.0)$ \\
Intolerance (\%) & $0(0)$ & $8(11.3)$ & $0(0)$ & $8(7.8)$ \\
Pouch enlargement (\%) & $1(6.7)$ & $5(7.0)$ & $2(11.8)$ & $8(7.8)$ \\
Band erosion (\%) & $1(6.7)$ & $3(4.2)$ & $1(5.9)$ & $5(4.9)$ \\
Band leak (\%) & $0(0)$ & $4(5.6)$ & $0(0)$ & $4(3.9)$ \\
GER (\%) & $0(0)$ & $4(5.6)$ & $0(0)$ & $4(3.9)$ \\
\hline
\end{tabular}

LAGB: Laparoscopic adjustable gastric banding; LRYGB: Laparoscopic roux-en-Y gastric bypass; LSG: Laparoscopic sleeve gastrectomy; GER: Gastroesophaseal reflux. 
deviation (SD) and independent samples t-test, One-Way ANOVA with Bonferroni correction or Pearson chi-square were performed as appropriate. Nonparametric data is presented as median (minimum-maximum) and tested using Mann-Whitney $U$ test, Kruskal-Wallis test or the Fisher's Exact test. The normal distribution of the variables was assessed using Kolmogorov-Smirnov test with Lilliefors Significance Correction or the Shapiro-Wilk test. Equality of variances was assessed using Levene's test. Significance was assumed as $p$ - value $<0.05$. Statistical analysis was performed using IBM SPSS Statistics ${ }^{\circledR}$ (Version 22; Armonk, NY: IBM Corp.) and Excel $2013^{\circledR}$ (2013; Redmond, WA: Microsoft Corp.).

\section{RESULTS}

From a pool of 103 cases that met the selection criteria, $15(14.6 \%)$ patients were subjected to LAGB, 71 (68.9\%) patients to LRYGB and $17(16.5 \%)$ to LSG, as RWLS. The LAGB, LRYGB and LSG groups had 14, 64 and 12 female patients, respectively.

In the LAGB group, $86.7 \%$ of reoperations were due to band slippage. In the LRYGB group, $46.5 \%$ and $19.7 \%$ of RWLS were a result of inadequate weight loss or band slippage, respectively. The main indications for LSG were band slippage (47.1\%) and inadequate weight loss (35.3\%). Overall, the most common complications of initial LAGB which lead to revision surgery were inadequate weight loss (37.9\%) and band slippage (34\%) (Table 1).

At initial LAGB, pre-operative BMI was $47.4 \pm 10 \mathrm{~kg} / \mathrm{m}^{2}$ in 14 individuals who underwent LAGB, $46.5 \pm 5.2 \mathrm{~kg} / \mathrm{m}^{2}$ in 69 from the LRYGB group and $47 \pm 7 \mathrm{~kg} / \mathrm{m}^{2}$ in 17 from LSG group ( $p$ - value $=0.872$ ). At removal, \%EWL in 36 patients converted to LRYGB was $27.2 \pm 35.4 \%$ and in 9 converted to LSG was $51.9 \pm 22 \%(p-$ value $=0.053)($ Table 2$)$.

Table 2 - Demographic characteristics, weight related measures and perioperative data at initial LAGB, at removal and at revision weight loss surgery (RWLS) in the laparoscopic adjustable gastric banding (LAGB), laparoscopic Roux-en-Y bypass (LRYGB) and laparoscopic sleeve gastrectomy (LSG) groups.

\begin{tabular}{|c|c|c|c|c|}
\hline & LAGB group & LRYGB group & LSG group & $p$ - value \\
\hline Number (\%) & $15(14.6)$ & $71(68.9)$ & $17(16.5)$ & \\
\hline Female (F:M) & $14(14)$ & $64(9.1)$ & $12(2.4)$ & 0.078 \\
\hline
\end{tabular}

$\mathbf{n}$

At initial LAGB

Age (years)

14

$36.6 \pm 8.9$

$47.4 \pm 10$

14

$57.2 \pm 22.7$

14

$3(2-9)$ n

n

\begin{tabular}{|c|c|c|c|c|c|c|c|}
\hline BMI $\left(\mathrm{kg} / \mathrm{m}^{2}\right)$ & 14 & $47.4 \pm 10$ & 69 & $46.5 \pm 5.2$ & 17 & $47 \pm 7$ & 0.872 \\
\hline EW (kg) & 14 & $57.2 \pm 22.7$ & 69 & $56.6 \pm 13$ & 17 & $59.6 \pm 22.6$ & 0.789 \\
\hline Stay (days) & 14 & $3(2-9)$ & 50 & $3(1-9)$ & 15 & $3(1-10)$ & 0.343 \\
\hline
\end{tabular}

At removal

$\begin{array}{lccccccc}\text { Age (years) } & 14 & 40.4 \pm 9.3 & 71 & 43.5 \pm 9.9 & 17 & 47.1 \pm 12.1 & 0.182 \\ \text { BMI (kg/m²) } & 8 & 42 \pm 7.45 & 36 & 40.5 \pm 8.3 & 9 & 36.1 \pm 6.8 & 0.253 \\ \text { \% EWL (\%) } & 8 & 31.2 \pm 25.1 & 36 & 27.2 \pm 35.4 & 9 & 51.9 \pm 22 & 0.132^{\dagger} \\ \text { Stay (days) } & 1 & 2 & 69 & 1(1-14) & 17 & 2(1-13) & 0.326^{\ddagger}\end{array}$

\section{At RWLS}

$\begin{array}{lccccccc}\text { Age (years) } & 15 & 40.3 \pm 9.4 & 71 & 44.9 \pm 9.8 & 17 & 48.4 \pm 12.1 & 0.081^{\Perp \prime} \\ \text { BMI }\left(\mathrm{kg} / \mathrm{m}^{2}\right) & 8 & 42 \pm 7.4 \S & 65 & 45.1 \pm 6.3 & 17 & 42.2(36.1-62.4) & 0.181 \\ \text { EW (kg) } & 8 & 42.9 \pm 17.2 & 65 & 52.7 \pm 16.1 & 17 & 45.6(27.6-89.9) & 0.204 \\ \text { Length of stay (days) } & 15 & 4(2-16) & 70 & 6(5-30) & 17 & 6(5-10) & 0.484 \\ \text { Total stay (days) } & \mathbf{1 4} & \mathbf{1 0 . 4 \pm \mathbf { 4 . 7 }} & \mathbf{4 7} & \mathbf{1 1 ( 8 - 3 4 )} & \mathbf{1 5} & \mathbf{1 1}(\mathbf{9}-\mathbf{3 0}) & \mathbf{0 . 2 6 9}\end{array}$

LAGB: Laparoscopic adjustable gastric banding; LRYGB: Laparoscopic Roux-en-Y gastric bypass; LSG: Laparoscopic sleeve gastrectomy; F:M: Female to male ratio; n: Number of patients; BMI: Body mass index; EW: Excess weight; \% EWL: Percentage of excess weight loss; RWLS: Revision weight loss surgery.

+ LRYGB vs LSG $p=0.053$, LAGB vs LSG $p=0.091$ and LAGB vs LRYGB $p=0.761$; $\neq P$-value for LRYGB vs LSG; $\S$ BMI at removal equal to BMI at RWLS because they were performed using a single-stage approach; $\|$ LAGB vs LSG $p=0.075$, LRYGB vs LSG $p=0.490$ and LAGB vs LRYGB $p=0.410$. 
In the LAGB group, mean time from the first bariatric surgery to removal was $3.2 \pm 1.5$ years in 13 cases and mean time to reoperation was $3.4 \pm 1.8$ years in 14 cases. All removals and reoperations were performed using a singlestage approach, except in one case where reoperation only occurred 2.3 years after removal. In patients who underwent LRYGB, using the two-stage approach, a mean period of $5.2 \pm 2.3$ years elapsed (measured in 55 patients) from the initial LAGB to removal, from removal to reoperation 0.92 years (maximum is 3.26 years) and from initial LAGB to reoperation $6.4 \pm 2.5$ years. In the LSG group, using the two-stage approach, the time between LAGB and removal was $6.1 \pm 2.3$ years, removal and reoperation $1.4 \pm 0.7$ years and from initial LAGB and reoperation $7.6 \pm 2$ years. Statistically significant differences were found between the LAGB and LRYGB groups (from LAGB to removal $p$ - value $=0.005$, from removal to reoperation $p-$ value $<0.001$ and from LAGB to reoperation $p$ - value $<0.001)$ and also between the LAGB and LSG groups ( $p$ - value $=0.001, p-$ value $<0.001$ and $p$-value $<0.001$, respectively).

The percentage EWL in the LAGB group at 1 month and at 3 months were significantly lower than in the other groups for the same points in time (Table 3).

\section{DISCUSSION}

Bariatric surgery results in greater weight loss and improvement of weight associated comorbidities when compared with non-surgical interventions. Outcomes are similar between RYGB and SG, and both of these procedures have better outcomes than LAGB. ${ }^{17}$ However, LAGB was widely used and with increasing follow-up times, complications and failure rates become clearer. ${ }^{10}$

A recent systematic review aggregated information on 514 patients who underwent LRYGB and 106 patients who underwent LSG as RWLS. The weighted mean for female to male ratios (F:M) were 23.4 and 9.1 , respectively. At revision, weighted mean for ages were $40 \pm 12$ years and $42 \pm 10.7$ years, respectively. Weighted mean for BMls were $43.3 \pm 8.1 \mathrm{~kg} / \mathrm{m}^{2}$ and $38.8 \pm 6.9 \mathrm{~kg} / \mathrm{m}^{2}$, respectively. Times to revision were $4.17 \pm 1.8$ years and $4.46 \pm 1.9$ years, respectively. ${ }^{15}$ In our study, the F:M ratios were lower, but the female predominance is obvious. Mean ages, BMIs and times to revision were higher. The differences between LRYGB and LSG groups regarding times to revision were well defined. Length of stay in our hospital is similar to other institutions in the LRYGB group while it is higher in the LSG group..$^{15}$

Furthermore, in the first 3 months, LRYGB and LSG are more effective than another LAGB surgery in terms of \%EWL. At 1 month, the LRYGB procedure appears to be more effective than the LSG, although the difference has no statistical significance. At 6 months, both are equally effective in reducing weight. Carr et $\mathrm{al}^{18}$ showed no difference between procedures with a longer follow-up,

Table 3 - Follow-up of revision weight loss surgery (RWLS)

\begin{tabular}{|c|c|c|c|c|c|c|c|}
\hline & \multicolumn{2}{|r|}{ LAGB group } & \multicolumn{2}{|c|}{ LRYGB group } & \multicolumn{2}{|r|}{ LSG group } & \multirow[t]{2}{*}{$p$-value } \\
\hline & $\mathbf{n}$ & & $\mathbf{n}$ & & $\mathbf{n}$ & & \\
\hline Follow-up (months) & 14 & $30 \pm 22.6$ & 66 & $7.1(0-44.5)$ & 16 & $4.3(0.5-20)$ & $<0.001^{* \mid}$ \\
\hline \multicolumn{8}{|l|}{ BMI $\left(\mathbf{k g} / \mathrm{m}^{2}\right)$} \\
\hline 1 month & 10 & $34.5 \pm 8.7$ & 50 & $37.9 \pm 6.5$ & 11 & $37.1 \pm 6$ & 0.352 \\
\hline 3 months & 9 & $38.5 \pm 6.8$ & 25 & $36 \pm 5.4$ & 8 & $34.6 \pm 5.1$ & 0.356 \\
\hline 6 months & 7 & $37.1 \pm 7.7$ & 17 & $34.8 \pm 6.7$ & 4 & $33.1 \pm 4.7$ & 0.622 \\
\hline 12 months & 2 & $31.4 \pm 0.9$ & 6 & $35.1 \pm 3.4$ & 1 & 33.4 & $0.199^{\ddagger}$ \\
\hline 18 months & 2 & $35.1 \pm 2$ & 4 & $33.1 \pm 5.7$ & 0 & & $0.576^{\ddagger}$ \\
\hline \multicolumn{8}{|l|}{$\%$ EWL (\%) } \\
\hline 1 month & 6 & $1.9 \pm 12.2$ & 49 & $36.9 \pm 18.2$ & 11 & $27.1(13.3-68.6)$ & $0.001^{\star \S}$ \\
\hline 3 months & 6 & $12.8(5.7-84.8)$ & 24 & $44.8 \pm 19.7$ & 8 & $48 \pm 20.1$ & $0.043^{* \|}$ \\
\hline 6 months & 4 & $22.1 \pm 35.4$ & 17 & $51 \pm 26.2$ & 4 & $50.4 \pm 21.9$ & 0.175 \\
\hline 12 months & 1 & 64.2 & 6 & $49.8 \pm 13.7$ & 1 & 46.1 & \\
\hline 18 months & 0 & & 4 & $52.4 \pm 25.7$ & 0 & & \\
\hline
\end{tabular}

LAGB: Laparoscopic adjustable gastric banding; LRYGB: Laparoscopic Roux-en-Y gastric bypass; LSG: Laparoscopic sleeve gastrectomy; n: Number of patients. * statistically significant; BMI: Body mass index; \% EWL: Percentage of excess weight loss.

+ LAGB vs LRYGB $p<0.001$, LAGB vs LSG $p=0.001$ and LRYGB vs LSG $p=0.219 ; \neq p$ - value for LAGB vs LRYGB; $\S$ LAGB vs LRYGB $p<0.001$, LAGB vs LSG $p=0.002$ and LRYGB $v s$ LSG $p=0.474 ; \|$ LAGB $v s$ LRYGB $p=0.017$, LAGB $v s$ LSG $p=0.039$ and LRYGB $v s$ LSG $p=0.691$. 
whereas Carandina et $\mathrm{al}^{19}$ found that LRYGB seems to guarantee greater weight loss than LSG, despite the fact that it is associated with higher postoperative morbidity.

A key principle of RWLS is converting a restrictive procedure to include a malabsortive component. ${ }^{15}$ However, when initial LAGB achieves adequate weight reduction and failure results from band slippage or pouch enlargement, similar outcomes from a different restrictive procedure are expected. When the reason for reoperation is inadequate weight loss, intolerance, band erosion or GER, a RYGB should be used. . $^{15,20,21}$

In our center, the choice of RWLS involves a multidisciplinary group constituted by bariatric surgeons, endocrinologists, nutritionists and psychiatrists that take into account the above mentioned principle and the surgeons' greater experience with LRYGB. But, the substantial difference between the number of LRYGB and LSG performed as revision is only partially explained by these aspects. An important factor that contributes to this discrepancy is the fact that the use of LSG as primary bariatric surgery and, specially, as revision surgery in the context of failed LAGB is very recent comparing with LRYGB. For example, in the United States of America, the Centers for Medicare and Medicaid Services (CMS) only approved the coverage of LSG as a stand-alone bariatric procedure on June 2012, stating that it should be done only in highly selected patients in qualified centers, and showing some reserves concerning the available evidence on patient selection, morbidity and mortality. ${ }^{22}$ Actually, evidence on long term outcomes is being published more consistently now, resulting from its increasing use (in Europe, from 2008 to 2011 , the number of SG done increased $571.8 \%)^{14}$ and longer follow-up times. ${ }^{23,24}$

RWLS is undoubtedly more challenging than primary surgery. ${ }^{25,26}$ In our study, the removal and RWLS in the LAGB group was performed using a single-stage approach, except in one case. All LRYGBs and LSGs were performed in a two-stage approach, except in one case of LRYGB. However, this strategy is not consensual. According to Van Nieuwenhove et al, ${ }^{27}$ a time interval after a band removal, might allow inflammation reduction of the upper gastric portion. In their series, there were no differences between the two conversion strategies in terms of weight loss,

\section{REFERENCES}

1. Lhachimi SK, Nusselder WJ, Lobstein TJ, Smit HA, Baili P, Bennett K, et al. Modelling obesity outcomes: reducing obesity risk in adulthood may have greater impact than reducing obesity prevalence in childhood. Obes Rev. 2013;14:523-31.

2. Utech $M$, Shaheen $H$, Halter J, Riege $R$, Knapp A, Wolf E, et al. Schlauchmagenbildung als revisionseingriff nach magenbandversagen. Zentralbl Chir. 2014;139:79-82.

3. Carreira H, Pereira M, Azevedo A, Lunet N. Effect of the type of population on estimates of mean body mass index and prevalence of overweight and obesity: a systematic review of studies of Portuguese adults. Ann Hum Biol. 2012;39:223-38

4. Global Health Observatory Data Repository, Overweight and Obesity Country Estimates 2008 (webpage on the internet). World Health Organization; 2013. [accessed 2013 Nov 15]. Available at: http://apps. who.int/gho/data/node.main.A900?lang=en.

5. Faria G, Preto J, da Costa EL, Guimaraes JT, Calhau C, Taveira-Gomes whereas morbidity and rate of anastomotic strictures were reduced. Recently, Aarts et al. ${ }^{28}$ concluded that the one-step RYGB conversion strategy is feasible and safe, but only when performed in specialized institutions and with great care in patient selection. This controversy also applies to SG as RWLS. ${ }^{26,29}$

The limitations of our study rely essentially in its design. Moreover, the implementation of LRYGB and LSG as RWLS in LAGB failure at CHSJ is relatively recent and consequently the follow-up periods for these procedures are relatively short. Another issue is the missing data, essentially due to the irregularity of patients' visits.

\section{CONCLUSIONS}

At our institution, the main indications for RWLS were inadequate weight loss and band slippage. LAGB as revision surgery is not an effective option, concerning the reduced weight loss, but LRYGB and LSG were both effective without statistical difference in short term (up to 6 months). At 6 months, there were no statistically significant differences between the three revision techniques. No differences in hospital stay between LAGB, LRYGB and LSG were observed. Longer follow-up periods are important in order to understand the long term effectiveness of LRYGB and LSG.

\section{PROTECTION OF HUMANS AND ANIMALS}

The authors declare that the procedures were followed according to the regulations established by the Clinical Research and Ethics Committee and to the Helsinki Declaration of the World Medical Association.

\section{DATA CONFIDENTIALITY}

The authors declare having followed the protocols in use at their working center regarding patient's data publication.

\section{CONFLICTS OF INTEREST}

The authors state no conflict of interests and have received no payment to perform this work.

\section{FUNDING SOURCES}

No subsidies or grants contributed to this work.

A. Acute improvement in insulin resistance after laparoscopic Rouxen-Y gastric bypass: is 3 days enough to correct insulin metabolism? Obes Surg. 2013;23:103-10.

6. Dixon JB, le Roux CW, Rubino F, Zimmet P. Bariatric surgery for type 2 diabetes. Lancet. 2012;379:2300-11.

7. Mingrone G, Panunzi S, De Gaetano A, Guidone C, laconelli A, Leccesi $L$, et al. Bariatric surgery versus conventional medical therapy for type 2 diabetes. N Engl J Med. 2012;366:1577-85.

8. Schauer PR, Kashyap SR, Wolski K, Brethauer SA, Kirwan JP, Pothier $\mathrm{CE}$, et al. Bariatric surgery versus intensive medical therapy in obese patients with diabetes. N Engl J Med. 2012;366:1567-76.

9. Ashrafian H, le Roux CW, Darzi A, Athanasiou T. Effects of bariatric surgery on cardiovascular function. Circulation. 2008;118:2091-102.

10. Tran TT, Pauli E, Lyn-Sue JR, Haluck R, Rogers AM. Revisional weight loss surgery after failed laparoscopic gastric banding: an institutional experience. Surg Endosc. 2013;27:4087-93. 
11. Lomanto D, Lee WJ, Goel R, Lee JJ, Shabbir A, So JB, et al. Bariatric surgery in Asia in the last 5 years (2005-2009). Obes Surg. 2012;22:502 6.

12. Buchwald H, Williams SE. Bariatric surgery worldwide 2003. Obes Surg. 2004; 14:1157-64.

13. Buchwald H, Oien DM. Metabolic/bariatric surgery worldwide 2008. Obes Surg. 2009;19:1605-11

14. Buchwald H, Oien DM. Metabolic/bariatric surgery worldwide 2011. Obes Surg. 2013;23:427-36.

15. Elnahas A, Graybiel K, Farrokhyar F, Gmora S, Anvari M, Hong D. Revisional surgery after failed laparoscopic adjustable gastric banding: a systematic review. Surg Endosc. 2013;27:740-5.

16. Franco JV, Ruiz PA, Palermo M, Gagner M. A review of studies comparing three laparoscopic procedures in bariatric surgery: sleeve gastrectomy, Roux-en-Y gastric bypass and adjustable gastric banding. Obes Surg. 2011;21:1458-68.

17. Colquitt JL, Pickett K, Loveman E, Frampton GK. Surgery for weight loss in adults. Cochrane Database Syst Rev. 2014;8:CD003641.

18. Carr WR, Jennings NA, Boyle M, Mahawar K, Balupuri S, Small PK. A retrospective comparison of early results of conversion of failed gastric banding to sleeve gastrectomy or gastric bypass. Surg Obes Relat Dis. 2015;11:379-84.

19. Carandina S, Maldonado PS, Tabbara M, Valenti A, Rivkine E, Polliand C, et al. Two-step conversion surgery after failed laparoscopic adjustable gastric banding. Comparison between laparoscopic Rouxen-Y gastric bypass and laparoscopic gastric sleeve. Surg Obes Relat Dis. 2014;10:1085-91.

20. Zundel N, Hernandez JD. Revisional surgery after restrictive procedures for morbid obesity. Surg Laparosc Endosc Percutan Tech. 2010;20:33843.

21. Ardestani A, Lautz DB, Tavakkolizadeh A. Band revision versus Roux-
en-Y gastric bypass conversion as salvage operation after laparoscopic adjustable gastric banding. Surg Obes Relat Dis. 2011;7:33-7.

22. ASMBS Frequently Asked Questions (FAQs) Regarding CMS Coverage for Laparoscopic Sleeve Gastrectomy. ASMBS; 2012. [accessed 2015 Jun 22]. Available at: http://asmbs.org/resources/asmbs-frequentlyasked-questions-faqs-regarding-cms-coverage-for-laparoscopicsleeve-gastrectomy.

23. Guetta O, Ovnat A, Shaked G, Czeiger D, Sebbag G. Analysis of morbidity data of 308 cases of laparoscopic sleeve gastrectomy-the Soroka Experience. Obes Surg. 2015;25:2100-5.

24. Carr WR, Jennings NA, Boyle M, Mahawar K, Balupuri S, Small PK. A retrospective comparison of early results of conversion of failed gastric banding to sleeve gastrectomy or gastric bypass. Surg Obes Relat Dis. 2015;11:379-84.

25. Hii MW, Lake AC, Kenfield C, Hopkins GH. Laparoscopic conversion of failed gastric banding to Roux-en-Y gastric bypass: short-term follow-up and technical considerations. Obes Surg. 2012;22:1022-8.

26. Yazbek T, Safa N, Denis R, Atlas H, Garneau PY. Laparoscopic sleeve gastrectomy (LSG)-a good bariatric option for failed laparoscopic adjustable gastric banding (LAGB): a review of 90 patients. Obes Surg. 2013;23:300-5.

27. Van Nieuwenhove Y, Ceelen W, Van Renterghem K, Van de Putte D, Henckens T, Pattyn P. Conversion from band to bypass in two steps reduces the risk for anastomotic strictures. Obes Surg. 2011;21:501-5.

28. Aarts E, Koehestanie P, Dogan K, Berends F, Janssen I. Revisional surgery after failed gastric banding: results of one-stage conversion to RYGB in 195 patients. Surg Obes Relat Dis. 2014:1077-84.

29. Silecchia G, Rizzello M, De Angelis F, Raparelli L, Greco F, Perrotta N, et al. Laparoscopic sleeve gastrectomy as a revisional procedure for failed laparoscopic gastric banding with a "2-step approach": a multicenter study. Surg Obes Relat Dis. 2014;10:626-31. 
Alfredo MENDES-CASTRO, Joana MONTENEGRO, Jorge Félix CARDOSO, Gisela SIMÕES, Catarina FERREIRA, John PRETO, Silvestre CARNEIRO

\section{Laparoscopic Adjustable Gastric Band: Complications, Removal and Revision in a Portuguese Highly Differentiated Obesity Treatment Center}

Acta Med Port 2015:28:735-740

Publicado pela Acta Médica Portuguesa, a Revista Científica da Ordem dos Médicos

Av. Almirante Gago Coutinho, 151

1749-084 Lisboa, Portugal.

Tel: +351218428 215

E-mail: submissao@actamedicaportuguesa.com

www.actamedicaportuguesa.com

ISSN:0870-399X | e-ISSN: 1646-0758

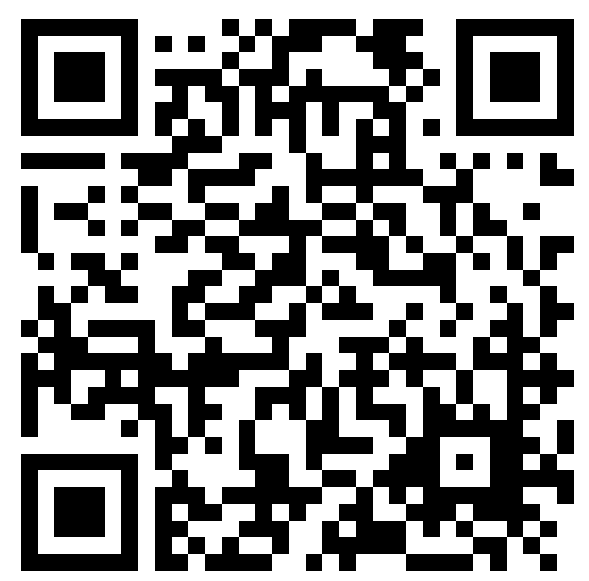

